\title{
Modelling nonlinear behavior of labor force participation rate by STAR: An application for Turkey
}

\author{
Sibel Cengiz ${ }^{1}$ and Afsin Sahin ${ }^{2}$
}

\begin{abstract}
The aim of this paper is to contribute to the understanding of the behavior of participation rates in terms of gender differences. We employed smooth autoregressive transition models for the quarterly Turkish labor force participation rates (LFPR) data between 2000: Q1-2011: Q4 to present an asymmetric participation behavior. The smoothness parameter indicates a gradual transition from low to high regimes. It is higher for female workers compared to the male workers. Participation rates diminish during a recession but they increase smoothly during the periods of expansion. The estimation results of Enders et al. (1998) also verified the asymmetry and nonlinearity in participation rates. During periods of economic expansion, they are higher than the threshold but the low regime indicator function takes the value zero. The results of the paper have economic implications for policy makers. Due to the discouraged worker and added worker effects, LFPR should be observed with the unemployment rates while evaluating the tightness of the labor market.
\end{abstract}

Keywords: Labor Force Participation Rate, Asymmetry, Nonlinear Behavior, STAR Model

JEL Classification: J21, E24, CO1

\section{Introduction}

Concerning labor market analysis, when economic activity declines, workers become discouraged and tend to leave the job market. During these times, inflow of additional workers and outflow of discouraged workers may create an equilibrium and leave LFPR unchanged, according to Strand et al. (1964). Because of discouraged and additional worker

1 Associate Professor of Economics, Department of Economics, Mugla Sitki Kocman University, Mugla, Turkey, scengiz@mu.edu.tr. Sibel Cengiz was a visiting scholar at the University of California, Berkeley Center for Labor Economics, USA between 01 October 2013 and 30 December 2013.

2 Associate Professor of Economics, Department of Banking, Gazi University, Ankara, Turkey, afsinsahin@gazi.edu.tr. 
effects, LFPR ${ }^{1}$ may be a better indicator concerning the labor market if economic activity declines compared to unemployment rates (see Mincer, 1962, Benati, 2001, Gustavsson et al., 2012). Therefore considering LFPR in addition to the unemployment rate may help policy makers to evaluate the tightness of the labor market (Gustavsson et al., 2007).

LFPR is related to unemployment and employment rates, and it is usually compared with these indicators to see if it is a more efficient indicator or not ${ }^{2}$. There are several papers trying to investigate the relationship between LFPR and unemployment rates. For instance, Emerson (2011) finds a long-run relationship between LFPR and the unemployment rate for the United States. Kakinaka et al. (2012) explore a cointegration relationship between LFPR and the unemployment rate for the male and fail to reject the null hypothesis for female workers in the Japanese economy. They emphasize the discouraged worker effect and claim if the unemployment rate increases at the same time, the LFPR may diminish. Besides, according to them, because of the added worker effect, young males are keen to be involved in the labor market when the unemployment rate is high. Especially during recessions, additional workers may enter the market to compensate for the diminishment in their household income due to being unemployed (see Lundberg, 1985 for the added worker effect). Due to these adverse conditions, households may decide to increase their labor supply (Hernandez et al., 2009). At the same time, the presence of a high unemployment rate during a recession period may lead unemployed workers to be withdrawn from the labor force whom are known as discouraged workers. Job searching costs may outweigh employment benefits during times of recession (Hartley et al., 1974). In this case, unemployment may be a significant variable negatively affecting the decision of entering the labor force (Mincer, 1966).

During business cycles, increasing unemployment also increases LFPR, but in the longer run, the relationship between LFPR and unemployment disappears according to Nickell (1995). Taking these factors into account, during macroeconomic shocks, it is also claimed that the unemployment rate does not reflect the actual situation in the labor market. One of the reasons is related with the discouraged workers effect. Thus LFPR should also be considered in those times (Koop et al., 1999).

This paper employs smooth autoregressive transition models for the quarterly Turkish LFPR data between 2000: Q1 - 2011: Q4 to present an asymmetric participation behavior. That seems plausible because when the shocks widen asymmetrically, the linear models may not be adequate for the nature of participation rates. Capturing the nonlinearity and asymmetry in LFPR is meaningful because the unemployment rate does not involve

\footnotetext{
${ }^{1}$ It is defined as the ratio of employment and unemployment to active population.

2 Fatih Ozatay who is the former vice president of the Central Bank of the Republic of Turkey claims that unemployment may decline because of a diminishment in LFPR. Thus, it should be considered while evaluating unemployment rate. (Ozatay, 2012). On the other hand, according to Elmeskov et al. (1993), there is a negative relationship between unemployment rates and LFPR for the OECD countries.
} 
the discouraged workers ${ }^{3}$. The paper is structured as follows. The second part reviews the literature briefly and discusses the macroeconomic variables for some countries including Turkey, and the data and the methodology are given. The third section is devoted to discussion and the concluding remarks. We included the Appendices within the web address $^{4}$.

\section{Data and Methodology}

We used the Turkish quarterly data spanning from 2000:Q1 to 2011:Q4. The graphs of the variables are presented in Appendix-A1. Data was gathered from the Turkish Statistical Institute (TurkStat). The stationarity properties of the data may offer some insight on the informative level of the variables. As seen in Appendix - A0, the unit root tests give mixed results. The Dickey Fuller tests tend to reject the null of non-stationarity but all of the ADF specifications fail to reject the unit root hypothesis. KPSS with trend and intercept values also tends to provide stationary results. When we look at the literature for other countries, the variables in question may give mixed results or non-stationary evidence. For instance, Gustavsson et al. (2006) claim that the LFPR in Australia, Canada and US are not stationary. If LFPR is stationary, then the unemployment rate may be transferred to the employment rate in the long-run (Gustavsson et al., 2006, p. 429). They tell us that if LFPR is non-stationary, then the unemployment rate cannot be used as an indicator of the labor market. The mean reversion is not valid also for the disaggregated LFPRs of sub-populations of the US economy according to Gustavsson et al., (2012). If the LFPR is not stationary, then the effectiveness of unemployment rates for measurement purposes would be problematic (Madsen et al., 2008, p. 167). The response of labor may change depending on employment prospects. It diminishes quickly but increases slowly (Madsen et al., 2008, p. 168). There is a case of mixed evidence for the LFPR concerning mean reverting properties (Madsen et al., 2008). Consequently they find mixed evidence for unemployment being a good indicator of joblessness. If there is a case of mean reverting in an unemployment rate, the probability of it being a good indicator of joblessness increases. They argue that the unemployment series in US are stationary nonlinear TAR processes (Caner et al., 2001). Salamaliki and Venetis (2014) use seasonally adjusted quarterly data for the US economy. They apply ADF unit root tests with constants and trends and explore the possibility that the participation rates are not stationary ${ }^{5}$.

Ozdemir et al. (2011) analyse the total, male and female participation rates for Australia, Canada and USA by multiple structural breaks. They claim that the structural

${ }^{3}$ Ozdemir et al. (2011, p 1) claim that unemployment rates are not informative during business cycles. Similarly Murphy et al. (1997) maintain that the unemployment rate is not a good informative rate for evaluating the job market.

${ }^{4} \mathrm{http}: / /$ websitem.gazi.edu.tr/site/afsinsahin/files.

5 Following the suggestions of the papers on the subject, we did not seasonally adjust the data, since the effects of seasonally adjusting on the nonlinear structure are not clear in the literature. 
breaks hinder the stationarity nature of the series. Gustavsson et al. (2006) and Madsen et al. (2008) claim that LFPR is not stationary, therefore the unemployment rate is not informative. However they claim that by the fractionally integrated method, the series are mean reverting and have structural breaks. They also mention that the unemployment rate is informative and may explain the movements in employment rates.

LFPR is the univariate variable we tried to model on smooth autoregressive models (STAR). STAR is one of the nonlinear econometric models based on the linear autoregressive model of Terasvirta (2004). Balcilar et al. (2011, p. 893) claim that because of the smooth transition consideration property of the STAR models, they are preferable compared to the threshold autoregressive models ${ }^{6}$ or the Markov switching models ${ }^{7}$. There is a sharp and discrete transition in threshold autoregressive models (TAR) and Markov switching models, but the transition is smooth with STAR or smooth transition regression (STR) models (Bonga, 2009). To do so, we applied the methodology defined in Terasvirta (2004) and the estimation steps as explained particularly in Kratzig (2005). Rather than using Jmulti to estimate the STAR or STR models, there are also programs such as $R, O x$, Matlab and to some extent, RATS. In this paper we preferred to use Jmulti essentially which is much simpler and make the work easier and more systematic ${ }^{8}$. On the other hand, JMulti has some restrictions and we should emphasize them. First of all, JMulti only allows for the logistic transition function, say the Logistic Smooth Transition Regression (LSTR1 or LSTR2), for modelling nonlinearity. - One can refer for the LSTAR versus ESTAR for Terasvirta (1994) and its replication for the RATS example files. The shape of the transition function is an essential distinction between the ESTAR and LSTAR models (see Ocal et al., 2000, p. 5).

In this paper, the LSTAR form defined in Terasvirta (2004) and Kratzig (2005) is given by the equation (1). See also Lundbergh and Terasvirta (2004) for the STAR model definitions. According to Sarantis (2001), the dynamics between the high and low regimes are not the same considering the LSTAR model.

$$
y_{t}=\left\{\phi_{t}+\theta G\left(\gamma, c, s_{t}\right)\right\}^{\prime} w_{t}+\varepsilon_{t} ; \quad \varepsilon_{t} \sim \operatorname{iii}\left(0, \sigma^{2}\right) ; t=1, \ldots, T .
$$

The first piece of the equation (1) with a parameter $\phi=\left(\phi_{0}, \phi_{1}, \ldots, \phi_{p}\right)^{\prime}$ inherits the linear part of the system, but the second piece of the equation represents the nonlinear part with the parameter $\theta=\left(\theta_{0}, \theta_{1}, \ldots, \theta_{p}\right)^{\prime}$. These parameter vectors are $(p+1) x 1$. $w_{t}^{\prime}=\left(1, y_{t-1}, \ldots, y_{t-p}\right)^{\prime}$ including the intercept and the first $p$ lagged values of the $y_{t}$. Note that if the model was a STR model, then there would be $z_{t}=\left(w_{t}^{\prime}, x_{t}^{\prime}\right)$ as a $(p+1) x 1$ vector of explanatory variables (parameter vectors) with intercept and $x_{t}^{\prime}=\left(x_{1 t}, \ldots, x_{k t}\right)^{\prime}$.

\footnotetext{
${ }^{6}$ See Tsay (1989).

7 See Hamilton (1989).

${ }^{8}$ We used RATS for the estimations in the Appendix.
} 
This is the difference between univariate models (STAR) and the multivariate model (STR). Since our model is univariate, we model the labor participation rate with STAR. The general logistic function in (2) represents the transition function and determines the behavior of the nonlinear part.

$$
G\left(\gamma, c, s_{t}\right)=\left(1+\exp \left\{-\gamma \prod_{k=1}^{K}\left(s_{t}-c_{k}\right)\right\}\right)^{-1}
$$

There are three parameters in the transition function. These are slope parameter $(\gamma)$, vector of location parameters $\left(c=\left(c_{1}, \ldots c_{K}\right)^{\prime}\right)$ representing the threshold among the regimes and the time varying transition parameter $\left(s_{t}\right)$. Note that the location parameter is increasing and the slope parameter is positive. - See Lundbergh et al. (2004, p. 486). If $K=1$, then the specification (1) and (2) are called logistic smooth transition functions (LSTAR1) and if $K=2$, it is called LSTAR2 (Terasvirta, 2004, p. 223). The model allows for an extreme transition between 0 and 1 and can be handled as a regime-switching model according to van Dijk et al. (2000, p. 2). LSTAR models had been extended as multiple regimes STAR (MRSTAR) models ${ }^{9}$.

Since our analysis is univariate, we do not have explanatory variables; therefore we estimated a STAR model rather than a STR model. So the maximum lag determined for the dependent variable $(y)$ is the LFPR. However we included seasonal dummy variables and a constant in the model as the deterministic part of the equation. First, we applied common linearity tests and selected the appropriate LSTAR specification. Table 1 presents the linearity test results for the LFPR of the total, male and female workers. The null hypothesis is to test linearity against non-linearity. At various lag lengths for all the variables, we rejected the null with the $F$ - statistics. We started from the lag length of 8 for the AR part and estimated the equations. The lags for 8 and 7 provided matrix inversion problem for the $p$-values of $F$-tests. We chose the appropriate model from several alternatives.

Table 1: Linearity Test Results

\begin{tabular}{|l|c|c|c|c|c|c|c|}
\hline Variables & $\begin{array}{c}\text { Transition } \\
\text { Variable }\end{array}$ & F & F4 & F3 & F2 & $\begin{array}{c}\text { Suggested } \\
\text { Model }\end{array}$ & $\begin{array}{c}\text { Optimal } \\
\text { Lag Length }\end{array}$ \\
\hline Total & Trend & 0.0003 & 0.4088 & 0.0228 & 0.0000 & LSTAR1 & 2 \\
\hline Male & Trend & 0.0364 & 0.6637 & 0.4884 & 0.0004 & LSTAR1 & 2 \\
\hline Female & Trend & 0.0002 & 0.0308 & 0.0651 & 0.0005 & LSTAR1 & 1 \\
\hline
\end{tabular}

For all the lags by the linearity tests the transition variable is chosen as the trend for total, male and female values. The LSTAR1 type model was chosen as the transition function for all the variables and lags. The meaning of LSTAR1 is that there is a monotonic

${ }_{9}$ See van Dijk et al. (1999) for the argumentation on the unemployment rate of the US economy. 
change of parameters through the linear to nonlinear part as a function of the trend in this case. Since the linearity tests indicate the case for LSTAR1 within the document, we also present the results for LSTAR2 in the Appendix-A2 where the parameters move symmetrically around the middle of the two location parameters. Terasvirta (2004, p. 224) claims that LSTAR1 may characterize the asymmetric behavior. Since the aim of the paper is to characterize the nature of asymmetry in participation rates, we evaluated the results for LSTAR1 model.

The initial values had been gathered by the grid search. Table 2 gives the initial values for the slope and location parameters. Next we determined the suggested LSTAR1 model by the $p$-values of the F4, F3 and F2 tests which has similar structures to the linearity test. For all the lags, the LSTAR1 type nonlinearity had been chosen. However it is interesting to note that when the trend as a transition variable is utilized, the value of SSR, gamma (slope) and $c 1$ increase if we diminish the lag.

Table 2: STR Grid Search

\begin{tabular}{|l|c|c|c|}
\hline & Total & Male & Female \\
\hline Transition variable & Trend & Trend & Trend \\
\hline Transition function & LSTAR1 & LSTAR1 & LSTAR1 \\
\hline Grid $c$ & $\{1.00,46.00,30\}$ & $\{1.00,46.00,30\}$ & $\{1.00,47.00,30\}$ \\
\hline Grid gamma & $\{0.50,10.00,30\}$ & $\{0.50,10.00,30\}$ & $\{0.50,10.00,30\}$ \\
\hline SSR & 13.4019 & 14.2355 & 26.7248 \\
\hline Gamma & 0.9293 & 1.7271 & 2.1235 \\
\hline$c 1$ & 1.0000 & 16.5172 & 13.6897 \\
\hline
\end{tabular}

Since the grid is constructed over $c_{1}, \gamma$ because of choosing LSTAR1, the panel (a) of Figure 2a is drawn by surface over these parameters. The panel (b) of Figure 2a is the contour plot of these. These figures are provided in Appendix - A3. The sum of residual square (SSR) is plotted as a function of $c, \gamma$. The initial one is the maximum SSR and the latter is the minimum SSR. str_resids ${ }^{2}$ is the square of the estimated residuals. A cross plot $G$ (Trend) is the graph of the transition function $G\left(\gamma, c, s_{t}\right)=\left(1+\exp \left\{-\gamma\left(s_{t}-c\right)\right\}\right)^{-1}$

for the LSTAR versus the transition variable (trend). The linear part $\left(\phi^{\prime} z_{t}\right)$, nonlinear part $\left(\theta^{\prime} z_{t} G\left(\gamma, c, s_{t}\right)\right)$, fitted series $\left(\phi^{\prime} z_{t}+\theta^{\prime} z_{t} G\left(\gamma, c, s_{t}\right)\right)$, original series $\left(y_{t}\right)$, transition function $\left(G\left(\gamma, c, s_{t}\right)\right)$ and the transition variable $\left(s_{t}\right)$ are graphed at the bottom of Figure 2a. The fitted series are the sum of the linear and nonlinear series. The average of the difference between fitted series and the original series is nearly zero. 
Modelling nonlinear behavior of labor force participation rate by STAR:

An application for Turkey

Table 3: STAR Estimation Results

\begin{tabular}{|c|c|c|c|c|c|c|c|c|c|}
\hline & \multicolumn{3}{|c|}{ TOTAL } & \multicolumn{3}{|c|}{ MALE } & \multicolumn{3}{|c|}{ FEMALE } \\
\hline Variables & Start & Estimate & $p$-value & Start & Estimate & $p$-value & Start & Estimate & $p$-value \\
\hline & \multicolumn{9}{|c|}{ Linear Part } \\
\hline Constant & 22.3750 & 91.3337 & [0.9528] & 14.1729 & 14.0890 & {$[0.3528]$} & 8.4350 & 8.1327 & [0.5010] \\
\hline Seas 1 & -4.0457 & -26.5723 & [0.9582] & -1.8728 & -1.9181 & {$[0.3376]$} & 1.0225 & 1.0239 & [0.4767] \\
\hline Seas2 & 8.5181 & 26.0472 & {$[0.9470]$} & 4.8109 & $4.8298 * *$ & {$[0.0143]$} & 7.0345 & $6.9971 * * *$ & [0.0017] \\
\hline Seas3 & 12.1940 & 56.4346 & [0.9547] & 4.9769 & 5.0356 & [0.0443] & 6.5435 & $6.4677^{* *}$ & [0.0213] \\
\hline$L F P R_{t-1}$ & -1.0923 & -11.3776 & {$[0.9607]$} & 0.4599 & 0.4516 & {$[0.2899]$} & 0.5414 & 0.5540 & [0.2401] \\
\hline \multirow[t]{2}{*}{$L F P R_{t-2}$} & 1.5524 & 10.2466 & {$[0.9580]$} & 0.3137 & 0.3232 & {$[0.5023]$} & & & \\
\hline & \multicolumn{9}{|c|}{ Nonlinear Part } \\
\hline Constant & -22.8334 & -92.4791 & [0.9522] & 4.6908 & 5.2539 & {$[0.8340]$} & -11.0820 & -10.7469 & [0.4395] \\
\hline Seas1 & 6.1355 & 29.0213 & [0.9544] & 2.6863 & 2.6972 & {$[0.3082]$} & -0.4901 & -0.4905 & [0.7799] \\
\hline Seas 2 & -4.9923 & -22.7658 & [0.9538] & -2.4812 & -2.4978 & {$[0.2945]$} & -3.3491 & -3.3103 & [0.1777] \\
\hline Seas3 & -12.2964 & -57.1991 & [0.9542] & -3.6908 & -3.7300 & {$[0.2266]$} & -4.9626 & -4.8841 & [0.1136] \\
\hline$L F P R_{t-1}$ & 2.8787 & 13.3213 & {$[0.9540]$} & 0.5729 & 0.5676 & [0.3941] & 0.5078 & 0.4939 & {$[0.3576]$} \\
\hline$L F P R_{t-2}$ & -2.3606 & -11.1956 & [0.9543] & -0.6300 & -0.6326 & {$[0.3755]$} & & & \\
\hline \multicolumn{10}{|l|}{$L F P R_{t-3}$} \\
\hline \multicolumn{10}{|l|}{$L F P R_{t-4}$} \\
\hline Gamma & 0.9293 & 0.5944 & [0.5465] & 1.7271 & 1.7422 & {$[0.3531]$} & 2.1235 & 2.1702 & [0.2721] \\
\hline$C 1$ & 1.0000 & -43.1529 & [0.9331] & 16.5172 & $16.0242^{*}$ & {$[0.0848]$} & 13.6897 & 13.9693 & {$[0.1223]$} \\
\hline
\end{tabular}

Note: ${ }^{* * *, * *}$ and ${ }^{*}$ indicate significance of the coefficients at $1 \%, 5 \%$ and $10 \%$ levels.

The parameters $c, \gamma, \theta, \phi$ are estimated by maximizing the conditional likelihood function automatically by the Newton-Raphson algorithm through benefiting the specification in JMulti. Smoothness parameter (gamma) is insignificantly positive and satisfies the restriction, and indicates a smooth transition from low to high periods of LFPR. The value of the gamma is higher for the female than the male workers indicating a sharper transition for the initial. The smoothness depends on or is controlled by the transition variable $^{10}$. The location parameter $(c)$ indicates that LFPR switches into the second regime. Location parameter is the threshold between regimes and may take different signs. This signals to us that the different magnitudes of the shocks may cause a shift among the regimes. Table 3 presents the results and Table 4 is for the diagnostic statistics. The null of no error autocorrelation failed to be rejected for Total (2 lags), Male (2, 4, 6, 8 lags) and Female (2, 4, 6, 8 lags). The parameter constancy is satisfied for Total (H1), Male (H1, H2) and Female (H1, H3). The ARCH-LM test with eight lags does not reject the null

${ }^{10}$ According to Balcilar et al. (2011, p. 894) if gamma is not significant, then the model should be interpreted as autoregressive model which is linear. 
of no conditional heteroskedasticity. In addition, the Jarque-Bera test of non-normality is rejected for total and female workers. The misspecification tests indicate the adequacy of the specifications.

Table 4: Diagnostic Statistics

\begin{tabular}{|l|c|c|c|}
\hline & Total & Male & Female \\
\hline AIC & -0.6286 & -0.5643 & -0.0539 \\
\hline$R^{2}$ & 0.9304 & 0.9011 & 0.9079 \\
\hline Variance of transition variable & 180.1667 & 180.1667 & 188.0000 \\
\hline Standard deviation of transition variable & 13.4226 & 13.4226 & 13.7113 \\
\hline Variance of residuals & 0.4171 & 0.4448 & 0.7635 \\
\hline SD of residuals & 0.6459 & 0.6669 & 0.8738 \\
\hline
\end{tabular}

Table 5: Test of No Error Autocorrelation

\begin{tabular}{|c|c|c|c|c|}
\hline Total & $\boldsymbol{F}$-value & $\mathbf{d f 1}$ & $\mathbf{d f 2}$ & $\boldsymbol{p}$-value \\
\hline 2 & 0.3537 & 2 & 28 & 0.7052 \\
\hline 4 & 8.6628 & 4 & 24 & 0.0002 \\
\hline 6 & 5.0395 & 6 & 20 & 0.0027 \\
\hline 8 & 5.3737 & 8 & 16 & 0.0021 \\
\hline Male & $\boldsymbol{F}$-value & $\mathbf{d f 1}$ & $\mathbf{d f 2}$ & $\boldsymbol{p}$-value \\
\hline 2 & 0.4677 & 2 & 28 & 0.6313 \\
\hline 4 & 1.9215 & 4 & 24 & 0.1394 \\
\hline 6 & 1.4141 & 6 & 20 & 0.2580 \\
\hline 8 & 1.8222 & 8 & 16 & 0.1461 \\
\hline $\boldsymbol{F e m a l e}$ & $\boldsymbol{F}$-value & $\mathbf{d f 1}$ & $\mathbf{d f 2}$ & $\boldsymbol{p}$-value \\
\hline 2 & 3.9041 & 2 & 31 & 0.0307 \\
\hline 4 & 1.4766 & 4 & 27 & 0.2369 \\
\hline 6 & 1.7192 & 6 & 23 & 0.1616 \\
\hline 8 & 1.6010 & 8 & 19 & 0.1900 \\
\hline
\end{tabular}

Note: The null is no error autocorrelation

Table 6: Test of No Remaining Nonlinearity

\begin{tabular}{|l|c|c|c|c|}
\hline \multicolumn{1}{|c|}{ Transition variable } & F & F4 & F3 & F2 \\
\hline Total $_{t-1}$ & 0.3210 & 0.2811 & 0.6970 & 0.1612 \\
\hline : $_{\text {- }}$ & 0.0021 & 0.0082 & 0.0749 & 0.1052 \\
\hline Female $_{t-1}$ & 0.3351 & 0.2907 & 0.3804 & 0.3793 \\
\hline
\end{tabular}

Note: Null is no remaining linearity. 
Table 7: Parameter Constancy Test

\begin{tabular}{|l|c|c|}
\hline Total & $\boldsymbol{F}$-value & $\boldsymbol{p}$-value \\
\hline H1 & 1.6427 & 0.1655 \\
\hline H2 & NaN & NaN \\
\hline H3 & NaN & NaN \\
\hline Male & $\boldsymbol{F}$-value & $\boldsymbol{p}$-value \\
\hline H1 & 0.9197 & 0.5478 \\
\hline H2 & 0.4948 & 0.8979 \\
\hline H3 & NaN & NaN \\
\hline Female & $\boldsymbol{F}$-value & $\boldsymbol{p}$-value \\
\hline H1 & 3.1310 & 0.0114 \\
\hline H2 & 1.8768 & 0.1232 \\
\hline H3 & 3.0467 & 0.1951 \\
\hline
\end{tabular}

Note: Null is parameter constancy.

Table 8: Other Tests

\begin{tabular}{|l|c|c|c|}
\hline & Total & Male & Female \\
\hline ARCH-LM test statistics with 8 lags & 9.8293 & 3.8185 & 7.178 \\
\hline$p$-value & {$[0.2772]$} & {$[0.8731]$} & {$[0.5176]$} \\
\hline$F$ - statistic: & 1.6574 & 0.5306 & 1.0996 \\
\hline$p$-value & {$[0.1519]$} & {$[0.8236]$} & {$[0.3908]$} \\
\hline & Total & Male & Female \\
\hline Jarque-Bera Test Statistic & 1.3875 & $20.5764^{* * *}$ & 1.6988 \\
\hline$p$-Value & {$[0.4997]$} & {$[0.0000]$} & {$[0.4277]$} \\
\hline Skewness & -0.3942 & 0.9667 & -0.2971 \\
\hline Kurtosis & 3.3198 & 5.6452 & 3.7172 \\
\hline
\end{tabular}

Note: ${ }^{* * *, * *}$ and ${ }^{*}$ indicate significance of the coefficients at $1 \%, 5 \%$ and $10 \%$ levels.

\section{Discussion and Concluding Remarks}

During the last ten years of the Turkish economy, although there were high economic growth rates, the unemployment rate did not diminish sufficiently, LFPR remained low and the registered number of people employed could not be increased, as stated by Papps (2011, p. 1). According to TurkStat (2012), as of February, 2012, the civilian labor force reached nearly 54.37 million people. Within the same period, the employed people were nearly 23.34 million and the number of unemployed people was 2.72 million. Besides, the 
employment rates were not high sufficiently and the unemployment rate was not lower in Turkey compared to growth rate (Table 9$)^{11}$.

Participation behavior during the economic crisis is an essential research agenda among economists. When the time series data exhibits asymmetry and nonlinearity during the recessions, LFPR diminishes. The unemployment rate may decrease because of diminishing LFPR or it may not reflect the real situation of the market. So when considering the unemployment rates we should also observe LFPR. During the post economic crisis period, the LFPR diminishes for female workers ${ }^{12}$. The participation decision of the labor in the course of macroeconomic shocks is connected to the coherence of the labor market to the fluctuations. However, during economic expansions, LFPR increases gradually. The shocks in the labor market spread asymmetrically in most of the theoretical and empirical papers. There are a variety of papers considering the asymmetric adjustment costs in labor market. When the economy shrinks, there is a high outflow of labor but when the economy expands, LFPR does not return to its old level quickly and there is an asymmetric situation (Madsen, et al., 2008).

The asymmteric behavior of the labor market is also supported in the literature for a variety of countries. The unemployment rates experienced by these countries may exhibit asymmetry and nonlinearity. Silvapulle et al. (2004) explain asymmetry, which means that the reaction of unemployment rate to output is not similar across different regimes of the economy. Pissarides and Mortenson (1993) measure asymmetry during the job creation and destruction periods. They claim that the job creation process takes more time compared to the job destruction one. According to McHugh (2002), there is an asymmetric behavior in unemployment rate. When the total demand diminishes, the unemployment rate does not diminish as quickly as the first case because of the rigidities in the labor market. Neftçi (1984) denotes that the unemployment data of the US economy exhibits asymmetric behavior. Delong et al. (1986) provide an emprical evidence that US unemployment is asymmetric during the business cycles. They claim that as a result of the rational expectations theory, if there is a case of asymmetry, the linear forecasts would not be optimal.

The asymmetry and nonlinearity are also supported for LFPR. For instance, Darby et al. (1998) estimate LFPR for US, Japan, France and Sweden in terms of age and sex for the period 1970 to 1995 . They conclude that the adaptation of LFPR to the shocks may be asymmetric during the high and low regimes. Gustavson et al. (2006) analyse the features

${ }^{11}$ Especially during the post crisis period in countries such as the US, the work hours per family have increased because the women are also included in the job market more frequently (Stiglitz, 2012, p. 14). We also observed a similar case for Turkey. Following the economic crises of 2000 and 2008, the women tended to get involved in the job market with a lag and by the increasing education level of women, LFPR tends to increase for women. See also the discussions in Gozgor (2013).

${ }^{12}$ The LFPR of women is historically low in Turkey and the non-farm activities should be increased by rural development programmes in rural areas. However, women in rural areas do not involve non-farm activities compared to men as mentioned by Rijkers et al. $(2012$, p. 1) and it is not an easy task for development programmes. 


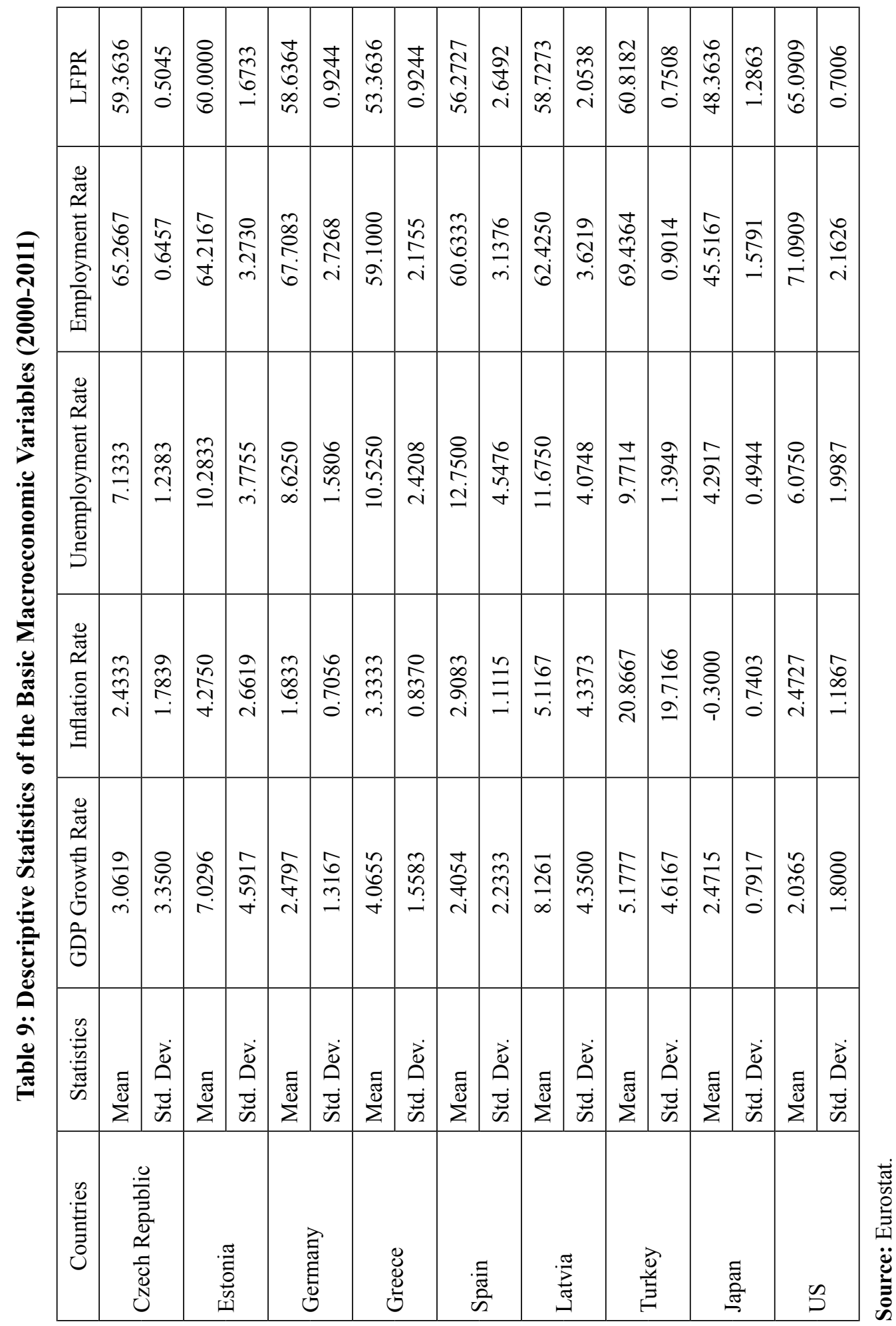


of LFPR for Australia, Canada and US for the monthly data of 1951-2004. They claim that LFPR series are not stationary by using the panel and univariate unit root tests.

We also estimated the Enders et al. (1998) methodology for Turkey to replicate the original paper. The test results also verified that there is an asymmetry and nonlinearity in LFPR. Participation rates behave differently for periods of recession and expansion in the economy. During the expansion LFPR is higher than the value of the threshold. The indicator function takes the value one. However in a reverse economic condition, the indicator function takes the value zero. And it can be claimed that the LFPR is lower than the threshold level. - Similar interpretation has been conducted of the unemployment rate by Enders (2006, p. 16). - See Appendix-B for the details of the test results.

Government subsidies would be beneficial to increasing the efficiency of the labor market. Betcherman et al. (2010) claim that the employment subsidies which aim to diminish the burden of employers in Turkey lower the informal employment levels, and encourage the registered employment and jobs in poor regions of Turkey. Moreover, the World Bank (2006) also claims that the reason for not creating sufficient employment was because of the cost for employers of severance pay.

\section{Acknowledgements}

The previous version of the paper had been presented at the 6th Annual International Conference on Mediterranean Studies, 26-29 March 2013, Athens, Greece. We would like to thank anonymous two referees for their valuable comments and suggestions. 


\section{References}

Balcilar, M., Gupta, R. and Shah, Z.B., 2011, 'An in-sample and out-of-sample empirical investigation of the nonlinearity in house prices of South Africa', Economic Modeling, 28, 3, pp. 891-899.

Benati, L. 2001, 'Some empirical evidence on the discouraged worker effect', Economics Letters, 70, 3, pp. 387-395.

Betcherman, G., Daysal, M. and Pages, C., 2010, 'Do employment subsidies work? Evidence from regionally targeted subsidies in Turkey', Labour Economics, 17, 4, pp. 710-722.

Bonga, L.B., 2009, 'Forward exchange rate puzzle: Joining the missing pieces in the randUS dollar exchange market', University of Johannesburg, Working Paper No. 122, http://www.econrsa.org/node/146, (accessed 5/1/2011).

Caner, M. and Hansen, B.E., 2001, 'Threshold autoregression with a unit root', Econometrica, 69, 6, pp. 1555-1596.

Chan, K.S., 1993, 'Consistency and limiting distribution of the least squares estimator of a threshold autoregressive model', The Annals of Statistics, 21, 1, pp. 520-533.

Darby, J., Hart, R.A. and Vecchi, M., 1998, 'Labour force participation and the business cycle: A comparative analysis of Europe, Japan and the United States', https://dspace. gla.ac.uk/bitstream/1905/577/1/9802.pdf, (accessed 29/1/2012).

Elmeskov, J. and Pichelmann, K., 1993, 'Interpreting unemployment: The role of labour force participation', OECD Economic Studies, 21(Winter), pp. 139-159.

Emerson, J., 2011, 'Unemployment and labor force participation in the United States', Economics Letters, 111, 3, pp. 203-206.

Enders, W. and Granger, C.W.J., 1998, 'Unit root tests and asymmetric adjustment with an example using the term structure of interest rates', Journal of Business and Economic Statistics, 16, 3, pp. 304-311.

Enders, W., Liu, Y. and Prodan, R., 2009, 'Forecasting series containing offsetting breaks: Old school and new school methods of forecasting transnational terrorism', Defense and Peace Economics, 20, 6, pp. 441-463.

Enders, W., 2010, Applied time series analysis, $3^{\text {rd }}$ Edition, Wiley Publication Incorporation, USA.

Enders, W., 2006, 'Forecasting persistent data with possible structural breaks: Old school and new school lessons using OECD unemployment rates', Working Paper, November, http://cba.unomaha.edu/faculty/mwohar/web/Frontiers-of-Forecasting/Enders_Prodan. pdf, (accessed 3/2012).

Gozgor, G., 2013, 'The New Keynesian Phillips Curve in an inflation targeting country: The case of Turkey', International Journal of Economic Sciences and Applied Research, 6, 1, pp. 7-18.

Granger, C.W.J. and Terasvirta, T., 1993, Modelling nonlinear economic relationships, Oxford University Press, Oxford. 
Gustavsson, M. and Österholm, P., 2012, 'Labor-force participation rates and the informational value of unemployment rates: Evidence from disaggregated US data', Economics Letters, 116, 3, pp. 408-410.

Gustavsson, M. and Österholm, P., 2007, 'Does unemployment hysteresis equal employment hysteresis?', The Economic Record, 83, 261, pp. 159-173.

Gustavsson, M. and Österholm, P., 2006, 'The informational value of unemployment statistics: A note on the time series properties of participation rates', Economics Letters, 92, 3, pp. 428-433.

Hamilton, J.D., 1989, 'A new approach to the economic analysis of nonstationary time series and the business cycle', Econometrica, 57, 2, pp. 357-384.

Hartley, M.J. and Revankar, N.S., 1974, 'Labor supply under uncertainty and the rate of unemployment', The American Economic Review, 64, 1, pp. 170-175.

Hernandez, R.D. and Romano, P.O., 2009, 'A cohort analysis of labor participation in Mexico 1987-2009’, IZA Working Paper No. 4371, http://www.iza.org/en/webcontent/ publications/papers/viewAbstract?dp_id=4371, (accessed 3/2011).

Kanika, M. and Miyamoto, H., 2012, 'Unemployment and labour force participation in Japan', Applied Economics Letters, 19, 11, pp. 1039-1043.

Koop, G. and Potter, S.M., 1999, 'Dynamic asymmetries in US unemployment', Journal of Business and Economic Statistics, 17, 3, pp. 298-312.

Kratzig, M., 2005, 'STR Analysis in Jmulti', Jmulti Documentation, http://www.jmulti.de/ download/help/str.pdf, (accessed 18/6/2011).

Ludberg, S., 1985, 'The added worker effect', Journal of Labor Economics, 3, 1, pp. 11-37.

Lundbergh, S. and Terasvirta, T., 2004, 'Forecasting with Smooth Transition Autoregressive Models', In: M.P. Celments and D.F. Hendry (eds.), A Companion to Economic Forecasting, Blackwell Publishing, USA, pp. 432-453.

Madsen, J., Mishra, V. and Smyth, R., 2008, 'Are labour force participation rates nonstationary? Evidence from 130 years for G7 countries', Australian Economic Papers, 47, 2, pp. 166-189.

Mchugh, Z., G. Bardsen and Hurn, S., 2002, 'A smooth-transition model of the Australian unemployment rate', Norwegian University of Science and Technology, Working Paper, No. 10, 2002, http://www.svt.ntnu.no/iso/wp/2002/10ausu.pdf, (accessed 10/7/2011).

Mincer, J, 1962, 'Labor force participation of married women: A study of labor supply', NBER, http://www.nber.org/chapters/c0603.pdf, (accessed 04/05/2012).

Mincer, J., 1966, 'Labor-force participation and unemployment: A review of recent evidence', In: R.A. Gordon and Gordon, H.S. (eds.), Prosperity and Unemployment, Wiley Publication, New York.

Murphy, K.M. and Topel, R., 1997, 'Unemployment and nonemployment', American Economic Review, 87, 2, pp. 295-300.

Neftçi, S.N., 1984, 'Are economic time series asymmetric over the business cycle?', Journal of Political Economy, 92, 2, pp. 307-328.

Nickell, S., 1995, 'Wages, unemployment and population change', L. Christophides, E. 
Grant and Swidinsky, R. (eds.), Aspects of Labour Market Behavior: Essays in Honor of John Vanderkamp, University of Toronto Press, Canada, pp. 71-102.

Ocal, N. and Osborn, D.R., 2000, 'Business cycle nonlinearities in UK consumption and production', Journal of Applied Econometrics, 15, 1, pp. 27-43.

Ozatay, F., 2012, 'Unemployment is sticky again', Radikal Gazetesi, June, 16. [In Turkish]. Ozdemir, Z.A., M. Balcilar and Tansel, A., 2011, 'International labour force participation rates by gender: Unit root or structural breaks?' Koç University-TUSIAD Economic Research Forum Working Paper Series, No. 1130.

Papps, K.L., 2011, 'The effects of social security taxes and minimum wages on employment: Evidence from Turkey', IZA Discussion Paper, No. 6214, December, http://ftp.iza.org/ dp6214.pdf, (accessed 10/1/2012).

Rijers, B. and Costa, R., 2012, 'Gender and rural non-farm entrepreneurship', World Bank Policy Research Working Paper No. 6066, 2012, http://elibrary.worldbank.org/content/ workingpaper/10.1596/1813-9450-6066, (accessed 12/2012).

Salamaliki, P.K. and Venetis, I.A., 2014, 'Smooth Transition Trends and Labor Force Participation Rates in the United States', Empirical Economics, 46, 2, pp. 629-652.

Silvapulle, P., Moosa, I. and Silvapulle, M.J., 2004, 'Asymmetry in Okun's Law', Canadian Journal of Economics, 37, 2, pp. 353-374.

Stiglitz, J. E., 2012, The price of inequality. USA: Norton Publications.

Strand, K. and Dernburg, T., 1964, 'Cyclical variation in civilian labor force participation', The Review of Economics and Statistics, 46, 4, pp. 378-391.

Terasvirta, T., 2004, 'Smooth Transition Regression Modeling'. In: Lutkepohl, H. and Kratzidg, M. (eds.) Applied Time Series Econometrics, Cambridge University Press, Cambridge.

Terasvirta, T., 1994, 'Specification, estimation, and evaluation of smooth transition autoregressive models', Journal of the American Statistical Association, 89, 425, pp. 208-218.

Tsay, R., 1989, 'Testing and modeling threshold autoregressive processes', Journal of the American Statistical Association, 84, 405, pp. 231-240.

TurkStat, 2012, 'Household labor force press release', TurkStat, Ankara, Turkey.

van Dijk, D., Terasvirta, T. and Franses, P.H., 2000, 'Smooth transition autoregressive models: A survey of recent developments', Econometric Institute Research Report No. 23/A, http://repub.eur.nl/res/pub/1656/feweco20000609141913.pdf, (accessed 4/2012). van Dijk, D. and Franses, P.H., 1999, 'Modeling multiple regimes in the business cycle', Macroeconomic Dynamics, 3, 3, pp. 311-340. 